\title{
KONSEP AUGMENTED REALITY DAN MOBILE MARKETING SEBAGAI USAHA PENGEMBANGAN PARIWISATA YOGYAKARTA DI ERA PANDEMI COVID 19
}

\author{
Diah Pradiatiningtyas \\ Universitas Bina Sarana Informatika,diah.ddt@bsi.ac.id
}

\begin{abstract}
ABSTRAK
Adanya kebijakan pembatasan kegiatan masyarakat secara serentak di sejumlah wilayah Jawa Bali atau PSBB Jawa Bali memunculkan kebijakan baru di sektor pariwisata Yogyakarta. Sektor Pariwisata di Yogyakarta harus beradaptasi dan mau tidak mau harus mengambil berbagai langkah strategis untuk tetap bertahan. Sebuah hal yang pasti adalah, adanya shifting pola masyarakat yang sebelumnya konvensional menjadi mobile. Augmented Reality (AR) merupakan salah satu bagian dari Virtual Environment (VE) atau yang biasa dikenal dengan Virtual Reality (VR). AR memberikan gambaran kepada pengguna tentang penggabungan dunia nyata dengan dunia maya. Sementara digital atau mobile marketing fokus kepada media dan konten apa yang akan dibuat untuk mempromosikan serta menjadi media komunikasi kepada wisatawan. Apalagi dengan penerapan protocol Kesehatan maka wisatawan memerlukan banyak informasi mengenai kunjungannya. Penelitian ini bertujuan menggambarkan konsep AR dan digital atau mobile marketing untuk mendukung pengembangan pariwisata Yogyakarta di era pandemic Covid 19. Metode penelitian yang digunakan adalah metode kualitatif deskriptif dengan pengambilan data secara kajian pustaka dan observasi. Kesimpulan yang di dapat dari penelitian sederhana ini adalah, augmented reality (AR) dapat dibangun menggunakan metode Multimedia Development Life Cycle dan digunakan bagi pelaku pariwisata dengan menghadirkan perangkat yang memadai. Digital marketing atau mobile marketing lebih mudah diterapkan dan menjadi alat promosi yang cocok di era pandemic covid 19 karena kemudahan akses dan pengoperasionalannya.
\end{abstract}

Kata Kunci: Pariwisata, Augmented Reality, Mobile Marketing, Digital Marketing, Covid 19

\section{ABSTRACT}

The policy of simultaneously restricting community activities in a number of areas of Java Bali or the PSBB Jawa Bali led to a new policy in the tourism sector in Yogyakarta. The tourism sector in Yogyakarta has to adapt and inevitably has to take various strategic steps to stay afloat. One thing that is certain is, there is a shifting pattern of society that was previously conventional to be mobile. Augmented Reality (AR) is one part of the Virtual Environment (VE) or commonly known as Virtual Reality (VR). AR provides an overview to the user about the merging of the real world with the virtual world. While digital or mobile marketing focuses on what media and content will be made to promote and become a medium of communication to tourists. Moreover, with the implementation of the Health protocol, tourists need a lot of information about their visit. This study aims to describe the concept of AR and digital or mobile marketing to support the development of tourism in Yogyakarta in the Covid 19 pandemic era. The research method used is a descriptive qualitative method with data collection by means of literature review and observation. The conclusion that can be obtained from this simple research is, augmented reality $(A R)$ can be built using the Multimedia Development Life

ISSN: 2355-6587, e-ISSN: 2528-2220

http://ejournal.bsi.ac.id/ejurnal/index.php/jp 
Cycle method and used for tourism actors by presenting adequate tools. Digital marketing or mobile marketing is easier to implement and is a suitable promotional tool in the Covid 19 pandemic era because of its easy access and operation.

Keywords: Tourism, Augmented Reality, Mobile Marketing, Digital Marketing, Covid 19

\section{PENDAHULUAN}

Pandemi covid 19 sudah berlangsung lebih dari satu tahun di Indonesia. Berbagai sektor telah terdampak imbasnya, mulai dari ritel raksasan satu per satu tumbang dan pastinya sektor Pariwisata juga terdampak buruk. Tak terkecuali pariwisata di Yogyakarta. Yogyakarta merupakan salah satu tujuan pariwisata yang utama di Indonesia selain Bali. Di awal terjadinya pandemi covid 19 ratarata obyek wisata di Yogyakarta harus menutup oprasional 3-4 bulan, sehingga pastinya pendapatan mengalami penurunan. Pada September 2020 pariwisata Yogyakarta sempat menggeliat karena kunjungan wisatawan lokal mulai mengalami peningkatan di akhir pekan, tak berlangsung lama karena angka penularan Covid 19 meninggi maka Pemerintah pun mengambil kebijakan PSBB. Adanya kebijakan pembatasan kegiatan masyarakat secara serentak di sejumlah wilayah Jawa Bali atau PSBB Jawa Bali pada 11-25 Januari 2021 turut memunculkan kebijakan baru di sektor pariwisata Yogyakarta.

Sektor Pariwisata di Yogyakarta harus beradaptasi dan mau tidak mau harus mengambil berbagai langkah strategis untuk tetap bertahan. Sebuah hal yang pasti adalah, adanya shifting pola masyarakat yang sebelumnya konvensional menjadi mobile dengan didukung teknologi informasi. Pemanfaatan mobilitas secara mobile oleh masyarakat meningkat di era pandemic covid 19 ini, hal tersebut bisa menjadi jawaban sektor pariwisata Yogyakarta untuk memanfaatkannya. Indonesia memiliki pertumbuhan populasi yang mengakses internet sebesar $17 \%$ dalam setahun terakhir.
Angka ini sama dengan 25.3 juta pengakses internet baru dalam setahun (Ramadhan, 2020). Di lihat pada September 2020 dimana sempat menggeliatnya pariwisata Yogyakarta oleh wisatawan lokal, maka pemanfaatan Augmented Reality yang dikolaborasi dengan digital marketing dapat ditawarkan sebagai konsep untuk memberikan kenyamanan bagi wisatawan dalam berkunjung dan tentunya pelaku pariwisata dapat memenuhi persyaratan pemerintah terkait aturan operasional obyek wisata selama Covid 19.

Augmented Reality (AR) merupakan salah satu bagian dari Virtual Environment (VE) atau yang biasa dikenal dengan Virtual Reality (VR). AR memberikan gambaran kepada pengguna tentang

$$
\text { penggabungan dunia nyata }
$$
dengan dunia maya dilihat dari tempat yang sama (Haryani dan Triyono, 2017). Sementara digital atau mobile marketing fokus kepada media dan konten apa yang akan dibuat untuk mempromosikan serta menjadi media komunikasi kepada wisatawan.

Penelitian ini bertujuan menggambarkan konsep AR dan digital atau mobile marketing untuk mendukung pengembangan pariwisata Yogyakarta di era pandemic Covid 19.

\section{Rumusan Masalah}

Rumusan masalah dalam penelitian ini adalah bagaimana konsep Augmented Reality dan digital atau mobile marketing yang dapat diterapkan untuk pariwisata Yogyakarta di era pandemic covid 19?

\section{Tujuan dan Manfaat Penelitian}

Tujuan dari penelitian ini adalah menngunkapkan konsep Augmented 
Reality dan digital atau mobile marketing yang dapat diterapkan untuk pariwisata Yogyakarta di era pandemi covid 19 dengan harapan manfaat pelaku pariwisata di Yogyakarta dapat menerapkannya untuk membantu pemulihan kondisi pariwisata yang dibarengkan dengan tetap memenuhi protokol kesehatan serta pemberian informasi yang jelas kepada wisatawan.

\section{KAJIAN LITERATUR}

\section{Pariwisata Yogyakarta}

Industri pariwisata dihadapkan pada penurunan yang besar dari kedatangan wisatawan mancanegara dengan pembatalan besar-besaran dan penurunan pemesanan. Penurunan juga terjadi karena perlambatan perjalanan domestik, terutama karena keengganan masyarakat untuk melakukan perjalanan. khawatir dengan dampak Covid-19. Penurunan bisnis pariwisata dan perjalanan berdampak pada usaha UMKM, dan terganggunya lapangan kerja. Padahal selama ini pariwisata merupakan sektor padat karya yang menyerap lebih dari 13 juta pekerja seperti dikutip dalam (Sugihamretha, 2020).

Tahun 2020 sektor Pariwisata DIY dihadapkan pada pandemi Covid19 dengan konfirmasi kasus Covid-19 pertama di Indonesia pada Senin 2 Maret 2020. Beberapa masa tanggap darurat diberlakukan di Yogyakarta secara berkala mulai tahun 2020 hingga 2021. Dalam masa tanggap darurat ini pun sektor pariwisata harus menutup sementara segala operasionalnya mulai Maret hingga Juni tahun 2020. Kawasan wisata di DIY pun mengalami kerugian. Kabupaten Gunung Kidul yang kehilangan sekitar Rp 100 milyar karena seluruh tempat wisata ditutup sementarasecara efektif sejak 24 Maret 2020 sementara Kabupaten Sleman yang mengalami penurunan pemasukan hampir $40 \%$ karena penutupan kawasan selama Maret hingga Mei tahun 2020 yang menyebabkan jumlah kunjungan menurun dari tahun sebelumnya yaitu tahun 2019 yang mencapai 10 juta wisatawan (Wicaksono, 2020).

Pentingnya sektor wisata dalam kegiatan pembangunan dan peluang pemasukan bagi industri pariwisata di DIY menjadi alasan penting pariwisata harus tetap dijalankan. Berdasarkan uraian tersebut maka pariwisata di DIY penyesuaian agar pengunjung tetap aman berwisata di tengah pandemi.

\section{Augmented Reality}

Augmented Reality (AR) adalah kombinasi antara dunia maya (virtual) dan duna nyata (real) yang dibuat oleh komputer. Obyek virtual dapat berupa teks, animasi, model 3D atau video yang digabungkan dengan lingkungan sebenarnya sehingga pengguna merasakan obyek virtual di lingkungannya. Augmented Reality adalah cara baru dan menyenangkan dimana manusia berinteraksi dengan komputer, karena dapat membawa obyek virtual ke lingkungan pengguna, memberikan pengalaman visualisasi yang nyata (Fernando, 2013).

\section{Digital Marketing dan Mobile Marketing}

Pemasaran digital atau digital marketing adalah praktek pemasaran yang menggunakan saluran distribusi digital untuk mencapai konsumen dengan cara yang relevan, personal dan cost-effective (Satyo, 2009).

Beberapa tahun belakangan ini, terjadi pergeseran dari komputer personal ke mobile communication/wireless. Hal ini dipicu semakin canggihnya sekaligus murahnya komputer dan telepon pintar. Akses kecepatan internet semakin baik dan munculnya berbagai konten digital mulai dari yang gratis hingga yang berbayar. Banyaknya jumlah pengguna ponsel membuat ponsel menjadi media massa baru, peluang ini dimanfaatkan oleh para pelaku usaha sebagai media untuk beriklan. Bagi para pemasar,

ISSN: 2355-6587, e-ISSN: 2528-2220

http://ejournal.bsi.ac.id/ejurnal/index.php/jp 
mobile marketing dianggap lebih efisien karena biaya murah, lebih fokus pada konsumen yang diinginkan sesuai target segmentasi, dan lebih terukur. Mobile marketing atau pemasaran seluler adalah strategi pemasaran digital multi-saluran yang ditujukan untuk menjangkau target konsumen di smartphone, tablet, dan perangkat seluler lainnya, melalui situs web, email, SMS dan MMS, media sosial, dan aplikasi.

\section{METODE PENELITIAN}

Penelitian ini merupakan penelitian deskriptif dengan pendekatan kualitatif. Pengambilan data berupa kajian pustaka dan observasi kepada media online yang dimiliki oleh beberapa obyek wisata di Yogyakarta. Data naratif dibuat dan disimpulkan untuk memenuhi jawaban atas permasalahan penelitian.

\section{PEMBAHASAN}

Penerapan augmented reality di
sektor pariwisata di Indonesia
sebenarnya sudah mulai digunakan.
Beberapa landmark sudah mulai
menggunakan AR.
mengembangkan AR di pariwisata maka ada beberapa langkah yang harus ditempuh yang berupa pengembangan sistem yaitu metode Multimedia Development Life Cycle seperti Gambar 1 yang mana menurut Indrawaty dkk (2013) dalam H dan Hendrati (2018) adalah sebagai berikut :

Pengkonsepan (Concept): Tahap pengonsepan (concept) adalah tahap untuk menentukan tujuan dan siapa pengguna program (audiens identification). Selain itu menentukan jenis aplikasi (presentasi, interaktif, dan lain-lain) dan tujuan aplikasi (hiburan, pembelajaran dan lain-lain). Dasar aturan untuk perancangan juga ditentukan pada tahap ini misalnya ukuran aplikasi, target aplikasi. Output dari tahap ini biasanya berupa dokumen yang bersifat naratif untuk mengungkapkan tujuan proyek yang ingin dicapai.

$$
\text { Perancangan (Design): }
$$

Perancangan (design) adalah tahap pembuatan spesifikasi meliputi arsitektur program, gaya, tampilan, dan kebutuhan material atau bahan untuk program. Spesifikasi dibuat serinci mungkin sehingga pada tahap berikutnya yaitu material collecting dan assembly, pengambilan keputusan baru tidak diperlukan lagi, cukup ini biasanya menggunakan storyboard untuk menggambarkan deskripsi tiap scene dengan mencantumkan semua objek multimedia dan tautan scene lain.

Pengumpulan Materi (Material Collecting): Pengumpulan materi adalah tahap pengumpulan bahan yang sesuai dengan kebutuhan yang dikerjakan. Bahan-bahan tersebut antara lain clip art, foto, animasi, video ataupun audio. Tahap ini dapat dekerjakan secara paralel dengan tahap assembly. Namun dapat juga tahap material collecting dan tahap assembly akan dikerjakan secara linear dan tidak paralel.

Pembuatan (Assembly): Tahap assembly adalah tahap pembuatan semua objek atau bahan multimedia dibuat. Pembuatan aplikasi didasarkan pada tahap design.

Pengujian (Testing): Tahap pengujian dilakukan setelah menyelesaikan tahap pembuatan (assembly) dengan menjalankan aplikasi atau program dan melihatnya apakah ada kesalahan atau tidak.

Distribusi (Distribution): Pada tahap ini, aplikasi akan disimpan dalam suatu media penyimpanan. Jika media penyimpanan tidak cukup menampung aplikasinya maka kompresi terhadap aplikasi itu akan dilakukan. Tahap ini juga dapat disebut tahap evaluasi untuk pengembangan produk yang sudah jadi supaya menjadi lebih baik. Hasil evaluasi ini dapat digunakan sebagai masukan untuk tahap concept pada produk selanjutnya. 


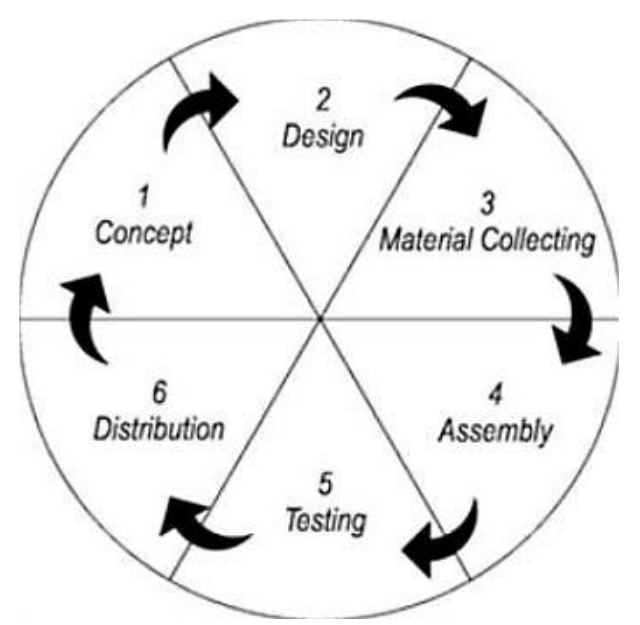

Gambar 1. Multimedia Development Life Cycle

Sumber: Indrawaty dkk (2013) dalam H dan Hendrati (2018)

\section{Penerapan Digital Marketing atau Mobile Marketing}

Beberapa pelaku pariwisata di Yogyakarta sudah mulai gencar menerapkan digital marketing atau mobile marketing. Dimana saat ini wisatawan yang memungkinkan berkunjung adalah wisatawan lokal atau domestik. Dengan adanya penerapan protocol kesehatan yang ketat jika ingin berkunjung, maka sudah menjadi kebutuhan bagi pelaku pariwisata atau pengelola untuk dapat benar-benar bisa mengkomunikasikannya dengan calon pengunjung agar mereka mempersiapkan sebaik mungkin. Selain untuk media komunikasi penerapan protocol Kesehatan dalam berkunjung, pengelola pariwisata perlu mempromosikan Kembali keunggulankeunggulan wisata yang dikelolanya, agar wisatawan memiliki referensi pariwisata dan tertarik mengunjungi dengan tidak lupa menerapkan peraturan tertentu.. Beberapa yang sudah diobservasi oleh peneliti berikut beberapa obyek wisata di Yogyakarta yang sudah mengadopsi digital marketing atau mobile marketing dengan baik

\section{Gembira Loka Zoo}

Pengelolaan Gembira Loka (GL) Zoo selama masa pandemi Covid-19 menjadi kebijakan penting yang patut dicontoh. Kebun binatang yang ada di Kecamatan Kotagede, Kota Yogyakarta itu sekarang ini sangat ketat menerapkan protokol kesehatan. Mereka gencar berpromosi menggunakan Instagram. Berikut gambar 2 halaman Instagram Gembira Loka Zoo.

\section{$\leftarrow$ glzoojogja2021}

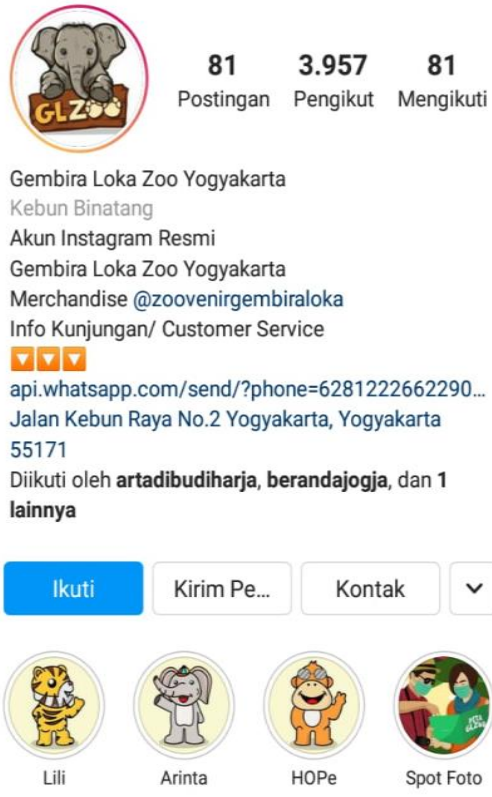

曲

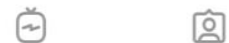

Gambar 2. Halaman Instagram Gembira Loka Zoo

Sumber: Observasi Penulis

Gembira Loka Zoo dalam pengamatan peneliti aktif berkomunikasi dengan pelanggan melalui Instagram dan melalui customer service yang bisa dihubungi secara mudah melalui aplikasi whatsapp. Gembira loka zoo pun membagikan informasi secara gencar untuk pesyaratan berkunjung secara terpusat, karena mereka tidak menerima kunjungan tanpa reservasi, selain itu penerapan cashless sudah dilakukan dengan melalui pembayaran transfer sebelum berkunjung.

Gambar 3 dibawah ini adalah halaman reservasi untuk berkunjung ke Gembira Loka Zoo: 


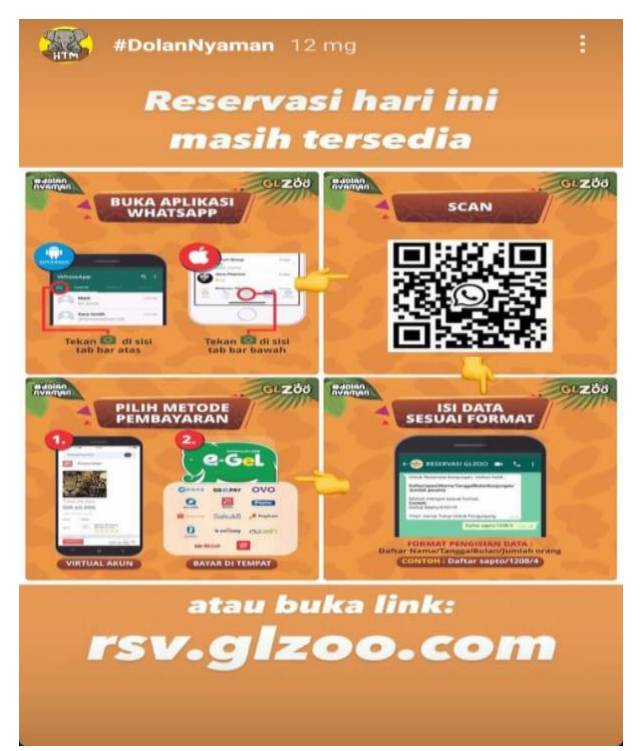

Gambar 3. Reservasi Online gembira Loka Zoo

Sumber: Observasi Penulis

\section{Heha Sky View}

Heha Sky View adalah destinasi kunjungan wisata yang tergolong baru karena baru diresmikan tahun 2019 dan langsung berhadapan dengan pandemi covid 19. Dengan segala peraturan yang ketat, mereka tetap berusaha beroperasi dan rajin menyapa pelanggan melalui media sosial Instagram. Pada halaman instagramnya pun mereka menginformasikan peraturan "New Normal" seperti tampak pada Gambar 4.

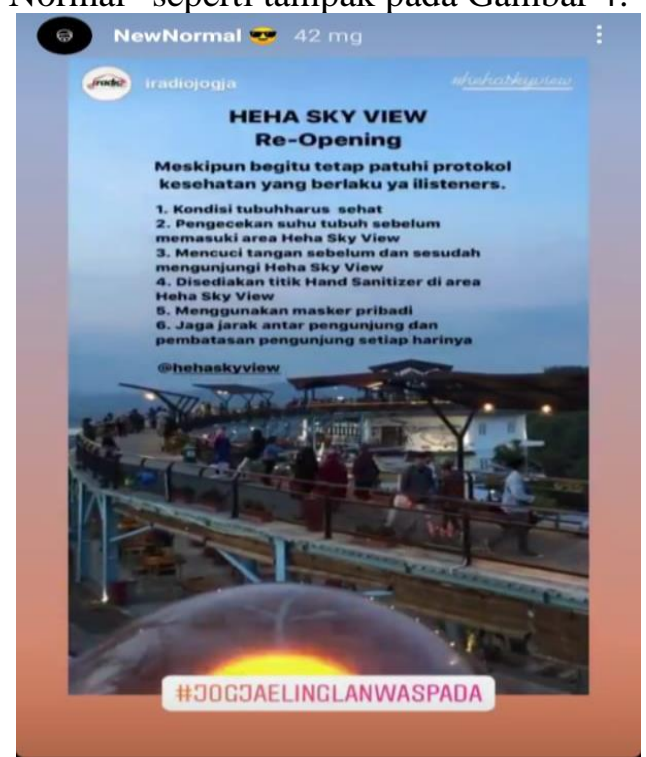

Gambar 4. Halaman Instagram Heha Sky View Era New Normal Sumber: Observasi Penulis
Dengan konsep AR calon wisatawan dapat diberikan pengalaman virtual untuk berkunjung tanpa datang secara langsung, hal tersebut dapat dimanfaatkan pengelola untuk menarik minat mereka berkunjung secara offline. Namun dari sisi perangkat dalam menyiapkan AR harus memadai, namun hasilnya dapat memberikan dampak yang baik. Seperti Google Maps yang saat ini dapat menampilkan obyek lokasi secara nyata melalui foto satelit dan memudahkan penggunanya melihat lokasi secara nyata.

Sementara digital marketing atau mobile marketing menjadi andalan banyak produsen di berbagai bidang maupun pelaku pariwisata. Karena kemudahannya dalam menjangkau pelanggan di belahan dunia manapun dan penggunaannya yang gratis. Pemaksimalan konten adalah hal yang utama agar informasi dapat tersampaikan dengan baik serta tentu saja menarik minat pelanggan. Media yang dapat digunakan secara mudah adalah Instagram, Twitter atau facebook. Tersedia pula Instagram Ads, dimana pengguna dapat melakukan iklan berbayar sesuai target pasar yang dituju. Selain itu biaya iklan pun dapat disesuaikan dengan kebutuhan penggunanya.

\section{PENUTUP}

Kesimpulan yang di dapat dari penelitian sederhana ini adalah, augmented reality (AR) dapat dibangun menggunakan metode Multimedia Development Life Cycle dan digunakan bagi pelaku pariwisata dengan menghadirkan perangkat yang memadai. Konten dan video dapat dipersiapkan sebagai bahan augmented reality. Hasilnya diprediksi dapat memberikan pengalaman berkunjung secara virtual kepada pelanggan. Sementara digital marketing atau mobile marketing lebih mudah diterapkan dan menjadi alat promosi yang cocok di era pandemic covid 19 karena kemudahan akses dan

ISSN: 2355-6587, e-ISSN: 2528-2220

http://ejournal.bsi.ac.id/ejurnal/index.php/jp 
pengoperasionalannya. Instagram, twitter, maupun facebook adalah media yang dapat digunakan karena banyak penggunanya, memiliki iklan dengan biaya terjangkau, selain itu penunjang call center seperti whatsapp dapat memudahkan komunikasi antara pelaku pariwisata dengan wisatawan sehingga dolan nyaman di Yogyakarta bisa dicapai.

Kedepannya diharapkan penelitian bisa lebih fokus pada penerapan AR kepada obyek wisata tertentu.

\section{REFERENSI}

H, Firdhaus Hari S., A dan Ovy Diansari Hendrati. (2018). Pemanfaatan Augmented Reality untuk Pengenalan Landmark Pariwisata Kota Surakarta. Jurnal TEKNOINFO, Vol. 12, No.1. 710.

Haryani, Prita dan Joko Triyono. (2017). Augmented Reality (AR) Sebagai Teknologi Interaktif dalam Pengenalan Benda Cagar Budaya kepada Masyarakat. Jurnal SIMETRIS, Vol 8 No 2 November. 807-812.

Ramadhan, Bagus. 2020. Data Internet di Indonesia dan Perilakunya Tahun 2020. https://teknoia.com/data-internetdi-indonesia-dan-perilakunya$880 \mathrm{c} 7 \mathrm{bc} 7 \mathrm{~cd} 19$

Satyo, Fatwan. (2009). Intellectual Capital. Gramedia Pustaka Utama, Jakarta.

Sugihamretha, I Dewa Gde. (2020). Respon Kebijakan: Mitigasi Dampak Wabah Covid-19 Pada Sektor Pariwisata. The Indonesian Journal of Development Planning. Volume IV No. 2. 191206.
Wicaksono, Ajie. (2020). New Normal Pariwisata Yogyakarta. Kepariwisataan: Jurnal Ilmiah. Volume 14 Nomor 3 September: $139-150$.

https://www.wartaekonomi.co.id/read31 9705/apa-itu-mobile-marketing

\section{BIODATA PENULIS}

Diah Pradiatiningtyas, SE., M.Sc. lahir di Yogyakarta 16 Agustus 1980. Menyelesaikan S1 di FEB UGM jurusan Manajemen dan S2 di Magister Sains UGM jurusan Ilmu Manajemen. Saat ini aktif sebagai Dosen di Universitas Bina Sarana Informatika Kampus Yogyakarta. Bidang yang diminati adalah pemasaran, e-commerce, digital marketing, dan pariwisata. Buku yang pernah diterbitkan antara lain DasarDasar Manajemen Bisnis dan Sistem Informasi Manajemen 